(2) Open Access Full Text Article

REVIEW

\title{
A novel misoprostol delivery system for induction of labor: clinical utility and patient considerations
}

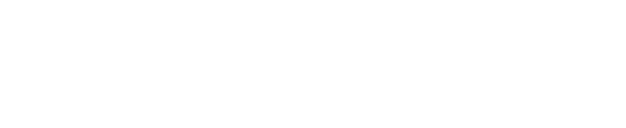

\section{Megan L Stephenson \\ Deborah A Wing}

Division of Maternal-Fetal Medicine, Department of Obstetrics and Gynecology, University of California, Irvine Medical Center, Orange, CA, USA
Correspondence: Megan L Stephenson Division of Maternal-Fetal Medicine, Department of Obstetrics and Gynecology, University of California, Irvine Medical Center, I0I The City Drive South, Building 56, Suite 800 ,

Orange, CA 92869, USA

Tel +l 7I44565967

Emailmfm@uci.edu

\begin{abstract}
Induction of labor is one of the most commonly performed obstetric procedures and will likely become more common as the reproductive population in developed nations changes. As the proportion of women undergoing induction grows, there is a constant search for more efficacious ways to induce labor while maintaining fetal and maternal safety as well as patient satisfaction. With almost half of induced labors requiring cervical ripening, methods for achieving active labor and vaginal delivery are constantly being investigated. Prostaglandins have been shown to be effective induction agents, and specifically vaginal misoprostol, used off-label, have been widely utilized to initiate cervical ripening and active labor. The challenge is to administer this medication accurately while maintaining the ability to discontinue the medication when needed. The misoprostol vaginal insert initiates cervical ripening utilizing a delivery system that controls medication release and can be rapidly removed. This paper reviews the design, development, and clinical utility of the misoprostol vaginal insert for induction of labor as well as patient considerations related to the delivery system.
\end{abstract}

Keywords: misoprostol, induction, cervical ripening, vaginal insert

\section{Introduction}

Induction of labor, ie, the iatrogenic provocation of contractions prior to the onset of spontaneous labor to achieve a vaginal delivery, has been a challenge to obstetricians, nursing units, and most importantly mother-baby pairs for decades. The rate of labor induction has increased considerably, with rates more than doubling from $9.5 \%$ in 1990 to almost a quarter of US pregnant women undergoing induction in 2012. ${ }^{1}$ In 2004 and 2005 , one in every five deliveries in the UK was induced. ${ }^{2}$ This rate has consistently increased in the UK, with rates of induction at around 23\% in England, Scotland, and Wales in 2012, and this trend is predicted to continue. ${ }^{3-5}$ Although previously thought to increase the cesarean delivery rate, more recent literature demonstrates that induction of labor is not associated with increased cesarean rates. ${ }^{6-8}$ While no large prospective trials have been conducted to confirm this, some authors of retrospective reviews comment that induction of labor may be associated with a decreased cesarean delivery rate, with no difference in perinatal morbidity or mortality. ${ }^{9-11}$ This includes a Cochrane review of induction of labor versus expectant management at or beyond term. ${ }^{12}$ Bailit et al recently published a retrospective cohort trial comparing expectantly managed women with women who underwent nonmedically indicated induction with nonanomalous, singleton, vertex pregnancies between 38 0/7 weeks and 41 6/7 weeks, and found that the cesarean risk curve was U-shaped with a nadir at 39 weeks. ${ }^{13}$ This is similar to the maternal and neonatal morbidity risk curve between these gestational ages. ${ }^{14}$ These associations are currently being studied in a large-scale randomized trial by the US National Institute of Child Health and Human Development Maternal Fetal 
Medicine Units Network. Although a change in guidelines has not been prompted as yet, the findings of this trial may result in more women being offered induction earlier in the term and late term.

Labor induction can often be a protracted process and maintaining the flow of patients from labor and delivery to the post partum unit while providing patient-centered quality care can be a challenge, and this balance may become more difficult as the number of women undergoing induction continues to rise. Regardless of the indication, induced labors can take multiple days and require thorough discussion to manage patient expectations. Although the debate about the connection between induction and cesarean delivery continues, the consequence of a failed induction also needs to be acknowledged. Ten percent of cesarean deliveries in the USA are being performed for failed induction. ${ }^{15}$ This rate is lower in other industrialized countries, with literature from Norway citing an induction failure rate of $4 \%{ }^{16}$ and about $3 \%$ in a large Australian population-based study. ${ }^{17}$ There are hopes that the rate in the USA will decrease with a more explicit definition of induction failure put forth by a workshop including the Eunice Kennedy Shriver National Institute of Child Health and Human Development, Society for Maternal-Fetal Medicine, and American College of Obstetricians and Gynecologists. ${ }^{15}$ The likelihood of a vaginal delivery is lower after induction versus spontaneous labor, especially in primiparous women with an unfavorable cervix..$^{15}$ As such, induction of labor in those women should be undertaken when there is a clear maternal or fetal benefit.

Up to half of induced labors require cervical ripening, which can be achieved using a variety of mechanical or chemical methods, including intracervical balloons or prostaglandin administration. Prostaglandins have been shown to increase vaginal delivery rates within 24 hours of labor induction and decrease the need for administration of oxytocin, with no effect on the rate of cesarean delivery in women with an unscarred uterus. ${ }^{18}$ However, they have also been shown to increase the rate of uterine tachysystole. This is an aspect of their use that requires careful consideration and analysis as new preparations are proposed.

Although the misoprostol vaginal insert (MVI) has not received US Food and Drug Administration (FDA) approval as of the most current report in 2014, it has successfully completed the European Decentralized Procedure involving 29 Member States of the European Economic Area, and the product, Misodel ${ }^{\circledR}$ (Mysodelle ${ }^{\circledR}$ in some European countries; Ferring Pharmaceuticals, Saint-Prex, Switzerland) is available widely in Europe. This paper reviews the MVI for induction of labor and the patient considerations associated with this delivery system.

\section{Overview of cervical ripening methods}

Successful induction of labor defined as a vaginal delivery is affected by a multitude of factors, some modifiable and some with greater impact than others. Parity, maternal age, body habitus, comorbidities, gestational age, and cervical status are all influencing elements. These factors should be assessed prior to starting an induction because success rates in general and those affecting a specific woman should be discussed. Cervical status can be scored and used as an indicator of the probability of successful induction. The modified Bishop score is the most commonly scoring system used clinically in the USA, and although it was initially described in multiparous women, ${ }^{19}$ it has been used with strong association in nulliparous women undergoing induction. ${ }^{20}$ Five factors are incorporated in the system, with points given for cervical dilation, effacement, station, consistency, and position, and high scores predicting a low rate of failed induction and a low score predicting a higher likelihood of success with labor induction. Laughon et al recently published results for a simplified scoring system using three of the original five factors that showed a similar or better positive predictive value, negative predictive value, positive likelihood ratio, and correct classification rate compared with the conventional five factor scoring system. ${ }^{21}$ Although the score thresholds found among different trials vary, in general a score $<6$ defines an unfavorable cervix and a score $>8$ is thought to have a vaginal delivery rate similar to that of a patient presenting in spontaneous labor. ${ }^{22}$ In cases of women with an unfavorable cervix, cervical ripening should be performed, and is required in almost half of all induced labors.

During spontaneous labor, the cervix undergoes a remodeling process where it absorbs water and becomes softer and more distensible. Induction agents attempt to mimic these normal changes either by mechanical or chemical means. Mechanical methods include membrane sweeping, intracervical balloon

( \pm$)$

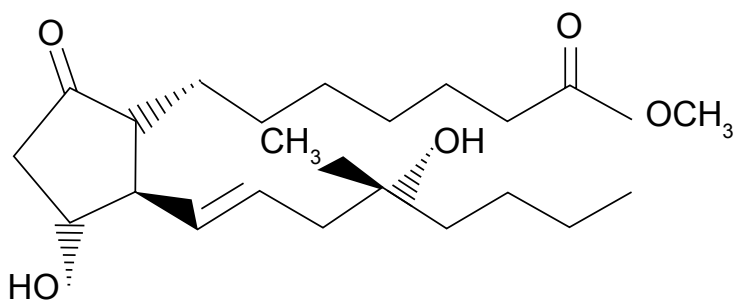

Figure I Prostaglandin EI. 
placement, and hygroscopic dilator placement, and are not reviewed here. Prostaglandin (PGE1 or PGE2) administration causes activation of collagenase, prompts remodeling of the extracellular matrix, generates uterine contractions, and may initiate labor. ${ }^{23}$ The two compounds have been investigated extensively and found to be effective induction agents that increase vaginal delivery rates within 24 hours, decrease the need for oxytocin administration, and have no effect on the cesarean rate in women with an unscarred uterus. ${ }^{24-26}$

Dinoprostone, a synthetic PGE2 analog, is currently available in several formulations in the USA and the European Union. The products include a cervical gel, a vaginal tablet, or a vaginal insert, and are administered locally within the reproductive tract. Prepidil ${ }^{\circledR}$ (Pfizer, New York, NY, USA) is a gel formulation that is introduced directly into the cervix; Prepidil $^{\mathbb{}}$ (Pfizer, New York, USA) is a gel formulation which is introduced directly into the cervix; Prostin E2 ${ }^{\circledR}$ (Pfizer, New York, USA) gel or tablet is administered intravaginally; Cervidil $^{\circledR}$ (Forest Laboratories, New York, USA)/Propess ${ }^{\circledR}$ (Ferring Controlled Therapeutics, Scotland, UK) is a controlled release formulation that has a retrieval tape allowing removal of the drug quickly and easily in case of excessive uterine stimulation. ${ }^{27,28}$

Misoprostol is a synthetic PGE1 analog and FDAapproved in an oral form (Cytotec ${ }^{\circledR}$; Pfizer) for use as a gastric protectant in patients treated with nonsteroidal antiinflammatory agents. Although not approved by the FDA for induction of labor, the oral tablet had been extensively used off-label vaginally, orally, and sublingually since the 1980s for cervical ripening and labor induction..$^{21,24,25,29}$ Hofmeyr et al published the results of one of the largest meta-analyses on labor induction, including 121 randomized controlled trials, of which 13 were double-blind, and found that compared with intracervical PGE2 and oxytocin, vaginal misoprostol in doses above $25 \mu \mathrm{g}$ every 4 hours was associated with fewer failures to achieve vaginal delivery within 24 hours and less need for oxytocin, although had a higher rate of uterine tachysystole with and without fetal heart rate changes. ${ }^{25}$ A $25 \mu \mathrm{g}$ tablet placed vaginally every 4 hours had similar efficacy to intravaginal or intracervical dinoprostone (PGE2) with regard to delivery time. ${ }^{25}$ Although this was a large metaanalysis, it should be highlighted that there were multiple dosing strategies and prostaglandin preparations compared, and the findings should be interpreted accordingly. A subsequent meta-analysis by Liu et al found similar results of a higher rate of vaginal delivery in 24 hours, with no change in cesarean rate but with higher rate of uterine tachysystole when specifically comparing intravaginal misoprostol with intracervical dinoprostone in singleton pregnant women with an unfavorable cervix at term. ${ }^{26}$ Advantages of misoprostol over dinoprostone include its low cost, stability at room temperature, and accessibility, although some of the drawbacks include the difficulty in dosing the tablet fragments accurately and the inability to discontinue the medication if uterine tachysystole or fetal heart rate tracing abnormalities arise. This prompted investigation into different dosing systems that would address these specific issues and generated the introduction of the MVI.

\section{Misoprostol vaginal insert delivery system}

The MVI is a single-application, removable, controlledrelease vaginal delivery system and is made from a nonbiodegradable hydrogel polymer with the active ingredient, misoprostol, dispersed throughout this polymer matrix. This polymer is then placed within an inert, woven retrieval tape. The reservoir of $200 \mu \mathrm{g}$ of misoprostol is released at a mean rate of approximately $7 \mu \mathrm{g}$ /hour while the insert remains in place, allowing constant dosing over a 24-hour period with the benefit of rapid and easy removal if needed. ${ }^{27,28}$ This is the same polymer as that used in the retrieval tape currently licensed for delivery of dinoprostone marketed as the dinoprostone vaginal insert (DVI, [Propess/Cervidil]). Labor physiology and the mechanism of action of misoprostol are reviewed here, including the pharmacodynamics and metabolism of this prostaglandin.

\section{Chemistry}

A group of cyclopentane derivatives of arachidonic acid, prostaglandins are involved in numerous physiologic processes. Most prostaglandins are short-lived and active only transiently, but there are some synthetic analogs that can have therapeutic effects. Misoprostol is a synthetic methyl ester analog of PGE1 in which the hydroxyl group at position 15 is absent and there is substitution of a methyl group and a hydroxyl group at position 16. It exists as a 1:1 mixture of two diastereoisomers, ie, $( \pm)-(\mathrm{S})$-misoprostol and $( \pm)-(\mathrm{R})$ misoprostol (Figure 1).

Blocks of the non-biodegradable polymer used for the insert are loaded with misoprostol. The properties of the hydrogel polymer allow it to absorb moisture and swell, but it does not dissolve. The absorption of water results in a concentration gradient, which facilitates the release of the loaded drug in a controlled-release manner. The hydrogel polymer should be inserted high into the posterior vaginal fornix using a small amount of water-soluble lubricant to aid insertion. 
Although studied most extensively in women with intact membranes, Castaneda et al found that a $\mathrm{pH}$ change related to ruptured membranes, vaginal secretions, or blood does not affect the release of misoprostol in vivo or in vitro. ${ }^{30}$ Frohn et al published results for women with premature rupture of membranes after 34 weeks who were randomized to receive dinoprostone gel or intravaginal misoprostol for cervical ripening, reporting that the misoprostol group had shorter delivery times without different cesarean rates, maternal, or neonatal outcomes, but with a higher tachysystole rate. ${ }^{31}$ Although these studies were not adequately powered to look for less common adverse effects, there is evidence that various prostaglandins can be used safely and effectively in women with ruptured membranes, in whom unfavorable cervical conditions may benefit from prostaglandin exposure..$^{30,31}$

\section{Pharmacodynamics, pharmacokinetics, and metabolism}

Misoprostol is used for its effect on cervical remodeling and uterine contractility, mimicking the changes that occur during normal labor. ${ }^{23-25}$ In particular, misoprostol stimulates remodeling of extracellular collagen with activation of collagenase, as well as increased water content and changes in the glycosaminoglycans of the extracellular matrix, with an increase in the amount of hydrophilic glycosaminoglycan and hyaluronic acid and a decrease in dermatan sulfate. ${ }^{23}$ It can also act within the uterine myocytes to directly increase myometrial contractility. ${ }^{23}$ All of these changes result in softening, effacement, and marked relaxation of the smooth muscle fibers and dilation of the cervix. Misoprostol is rapidly deesterified to its free acid, misoprostol acid, which is an active metabolite. Only the free acid is detectable in plasma, and it is further metabolized to inactive compounds prior to excretion. Misoprostol is extensively absorbed and rapidly metabolized, with approximately $80 \%$ excreted by the kidney with a terminal half-life of less than 1 hour when dosed vaginally, and peak plasma levels noted at around 5-9 hours..$^{27,32}$ Median plasma misoprostol acid concentrations after removal of dose-ranging, controlled-release MVI were reported by Rayburn et al who found that plasma levels decreased logarithmically and became very low $(5 \mathrm{pg} / \mathrm{mL})$ at 2 hours post-removal in all dose reservoirs $(25,50,100,200$, and $300 \mu \mathrm{g}){ }^{28}$

\section{Clinical application Phase I trials}

Assessment of the pharmacokinetic properties of the MVI has been completed in both nonpregnant women and pregnant nulliparous women in Phase I trials. In their study of nonpregnant women, Powers et al recorded the pharmacokinetic parameters for misoprostol acid after application of misoprostol 100, 200, and $400 \mu \mathrm{g}$ vaginal inserts for 24 hours. They found that the area under the plasma concentration versus time curve (AUC) from time 0 to the last measurable concentration ( $0-24$ hours) and peak plasma concentration $\left(\mathrm{C}_{\max }\right)$ parameters were dose-proportional, with lower-dose reservoirs associated with lower plasma levels, medium dose reservoirs with medium levels, and the highest dose reservoirs with the highest pharmacokinetic levels. ${ }^{27}$ These results are similar to those found by Rayburn et al in their open-label, dose-escalation study of 51 pregnant nulliparous women. ${ }^{28}$ Pharmacokinetic parameters were recorded after MVI dosing with 25, 50, 100, 200, and $300 \mu \mathrm{g}$ after varying durations of insertion due to varied removal times for onset of labor or adverse events. $\mathrm{AUC}_{0 \text {-removal }}$ (AUC from time 0 to removal), $\mathrm{AUC}_{0-\mathrm{t}}$ (AUC from time 0 to the last measurable concentration), and $\mathrm{C}_{\max }$ for misoprostol acid were dose-proportional between the $25 \mu \mathrm{g}$ and $300 \mu \mathrm{g}$ reservoir doses. ${ }^{28}$ Both studies found that misoprostol acid in plasma was quickly eliminated from the systemic circulation, with a terminal half-life of less than 1 hour in both pregnant and nonpregnant women. ${ }^{27,28}$ In pregnant women, each MVI released approximately $50 \%$ of the drug by 12 hours and $80 \%$ by 24 hours, with misoprostol released at a rate that was proportional to the dose reservoir. ${ }^{28}$

\section{Phase II trials}

Ewert et al conducted a randomized, double-blind, dose-ranging study in 124 women using dose reservoirs of $25,50,100$, and $200 \mu \mathrm{g}$, and found that the percentage of women delivering vaginally within 12 hours increased with increasing dose compared with the $25 \mu \mathrm{g}$ reservoir $(9 \%, 14 \%, 47 \%$, and $53 \%$, respectively, $P<0.001) .{ }^{33}$ They found uterine hyperstimulation syndrome in one woman in the $25 \mu \mathrm{g}$ group, two women in the $100 \mu \mathrm{g}$ group, and three women in the $200 \mu \mathrm{g}$ group. ${ }^{33}$ Castaneda et al published similar results for their multicenter, dose-escalating investigation using the same dosing reservoirs in addition to a $300 \mu \mathrm{g}$ dose reservoir and found that the mean time to vaginal delivery for the $25,50,100,200$, and $300 \mu \mathrm{g}$ groups was $43,33,15,12$, and 15 hours, respectively. ${ }^{30}$ They concluded that the doses had increasing efficacy up to the $100 \mu \mathrm{g}$ dose reservoir, above which there was no better efficacy and more uterine hyperstimulation. The safety and efficacy results of these two Phase II trials were discussed with the FDA, and the decision was taken to conduct a Phase III trial using the $50 \mu \mathrm{g}$ and $100 \mu \mathrm{g}$ misoprostol dose reservoirs, with 
the DVI as the blinded comparator, ${ }^{34}$ after which an additional Phase II trial was completed, ${ }^{32}$ and is reviewed below.

\section{Phase III trials}

The first Phase III trial of the MVI was completed in 2007, and was a double-blind, multicenter, randomized controlled trial comparing the MVI $50 \mu \mathrm{g}$ and MVI $100 \mu \mathrm{g}$ inserts with the controlled-release DVI insert in 1,308 women with singleton pregnancies of at least 36 weeks' gestation. ${ }^{34}$ This study included women with a parity of 3 or less, a Bishop score $<4$, and a body mass index $<50$. It excluded: women in active labor; those with a uterine scar or malformation, pre-eclampsia marked by hemolysis, elevated liver enzymes and low platelets, or evidence of end organ dysfunction such as central nervous system involvement other than mild headache, fetal malpresentation, or anomaly; evidence of fetal compromise; fever or evidence of chorioamnionitis; or any condition requiring urgent delivery. Also, the women could not have had amnioinfusion of tocolysis prior to initiation of induction. Oxytocin was held until 30 minutes after removal of the study drug to avoid additive effects of using both agents together.

The results showed that the MVI $100 \mu \mathrm{g}$ and the DVI had similar efficacy with respect to median time to delivery (1,596 minutes for the MVI $100 \mu \mathrm{g}$ and 1,650 minutes for the DVI), while the MVI $50 \mu \mathrm{g}$ took significantly more time to achieve vaginal delivery $(2,127$ minutes, $P<0.01)$. Cesarean rates were similar.

A secondary analysis was carried out by Pevzner et al who found that the MVI $50 \mu \mathrm{g}$ was associated with fewer cardiotocographic abnormalities (15.3\%) than the MVI $100 \mu \mathrm{g}$ group $(25.9 \%, P<0.001)$ and the DVI group $(27.1 \%$, $P<0.001) .^{35}$ The initial Phase III $^{34}$ result prompted a reexamination of the optimal effective dose reservoir that maintained safety, and an additional Phase II trial was conducted by Wing et al who analyzed the 100, 150, and $200 \mu \mathrm{g}$ reservoirs in 374 women. ${ }^{36}$ They found that women treated with the $200 \mu \mathrm{g}$ MVI entered active labor more rapidly than those treated with the $100 \mu \mathrm{g}$ or $150 \mu \mathrm{g}$ MVI, with a median time to active labor of 1,069 (range 885-1,153) minutes for the MVI $100 \mu \mathrm{g}, 775$ (range 724-977) minutes for the MVI $150 \mu \mathrm{g}(P=0.16)$, and 701 (range 550-759) minutes for the MVI $200 \mu \mathrm{g}(P=0.01)$. The $200 \mu \mathrm{g}$ MVI group had more vaginal deliveries in $<12$ hours than the $100 \mu \mathrm{g}$ MVI group $(P=0.02)$ and reduced oxytocin augmentation $(48.9 \%$ versus $70.9 \%, P<0.001$, relative risk $0.70,95 \%$ confidence interval [CI] 0.56-0.85). Of the women who delivered vaginally, those in the $200 \mu \mathrm{g}$ MVI group delivered more than 9 hours more rapidly than those in the $100 \mu \mathrm{g}$ group $(1,181$ [range
$1,035-1,443]$ minutes, $P=0.02)$. The cesarean rate between the three arms was not different; however, the $200 \mu \mathrm{g}$ MVI group had more episodes of uterine tachysystole. ${ }^{36}$

Given the safety implications of these findings, a secondary analysis was undertaken by Stephenson et al to assess the cardiotocographic abnormalities associated with the different misoprostol dosing reservoirs. ${ }^{37}$ Again, the rate of uterine tachysystole was higher in the $200 \mu \mathrm{g}$ MVI group than in the $100 \mu \mathrm{g}$ MVI group $(P<0.001$, relative risk $2.11,95 \%$ CI 1.39-3.22); this effect was not noted between the $150 \mu \mathrm{g}$ and $100 \mu \mathrm{g}$ dose reservoirs. Cases of tachysystole starting when the drug was in situ occurred more often with the $200 \mu \mathrm{g}$ MVI dose than with the $100 \mu \mathrm{g}$ MVI dose $(P<0.001$, relative risk $2.65,95 \%$ CI 1.62-4.33). However, uterine hyperstimulation syndrome, defined as tachysystole with fetal heart rate abnormality, was not significantly different between the groups. The cesarean delivery rate was also similar between the groups. Most importantly, in patients who had a cesarean delivery, the mean time from onset of tachysystole to delivery was $8.3,17.7$, and 15.5 hours for the 100,150 , and $200 \mu \mathrm{g}$ dose reservoirs, respectively, indicating that very few of these deliveries, if any, were performed for emergent fetal indications related to fetal heart rate abnormality. ${ }^{37}$

A second and similarly designed Phase III trial was then conducted, comparing 1,358 women randomized to receive the $200 \mu \mathrm{g}$ MVI or the DVI. ${ }^{38}$ Time to vaginal delivery and rate of cesarean delivery were the coprimary endpoints, with secondary endpoints of time to any delivery mode, time to onset of active labor, and use of oxytocin. When compared with women treated with the DVI, women treated with the $200 \mu \mathrm{g}$ MVI had significantly reduced times to vaginal delivery and active labor as well as a reduced need for oxytocin. ${ }^{38}$ Cesarean delivery rates were similar, as were fetal heart rate changes, overall rates of category II and category III fetal heart rate tracings, and adverse events, between the two groups. There was more use of tocolysis in the MVI group (relative risk 2.97, 95\% CI 1.96-4.50) and more meconium noted in amniotic fluid (relative risk 1.31, 95\% CI 1.02-1.68) than in the DVI group when the two groups were compared. ${ }^{38}$ However, there were no differences in 1-minute or 5-minute Apgar scores, neonatal encephalopathy, neonatal intensive care admission, neonatal intravenous or intramuscular antibiotic use, neonatal respiratory events, or neonatal brain disorders noted between the two treatment groups.

\section{Safety}

Paramount in the development of a drug or dosing system is a thorough assessment of maternal and neonatal safety. 
Although the increased rate of uterine tachysystole in these studies did not translate into a higher cesarean rate or a difference in neonatal or maternal adverse outcomes, there is limited ability to assess what other effects this may have. A hypothesized effect of uterine tachysystole is postpartum hemorrhage, although the rates of hemorrhage were no different in women included in multiple trials of the MVI with and without uterine tachysystole. ${ }^{35-38}$ In both secondary analyses analyzing cardiotocographic changes with use of the MVI by Pevzner et $\mathrm{a}^{35}$ and Stephenson et $\mathrm{a}^{37}$ a large number of the subjects were noted to have fetal heart rate changes and uterine tachysystole, but the cesarean rates and adverse outcomes were no different between the groups, although the studies were not powered for that particular outcome. In addition, of the 41 participants in the analysis by Stephenson et al who had a cesarean delivery secondary to a cardiotocographic abnormality, had an interval of longer than 2 hours from removal of the study drug to time of cesarean section, indicating that these deliveries were unlikely to have been due to a drug effect while in situ. ${ }^{37}$

As in previous trials, there was no clear difference in neonatal outcomes between the two groups in the most recent Phase III trial, ${ }^{38}$ although some rare outcomes were not able to be assessed accurately because the study was not powered to detect statistically significant differences in these less frequent neonatal outcomes. Investigators attempted to evaluate these rare events in the initial Phase III trial by having an independent, blinded expert panel consisting of board-certified perinatologists and neonatologists conduct a post hoc review of the details of each complicated case. ${ }^{34}$ The panel concluded that none of the cases had plausible links between specific adverse events and the study drug, and that larger studies need to be performed to better analyze these risks.

\section{Patient perspective}

Induction of labor can be a long and tiring experience for women, and patient satisfaction should be taken into account when choosing an induction method. There are limited data on women's experience of induction of labor. Gatward et al found that the feelings of women undergoing induction varied, with some women feeling as though they were not given a choice in the matter or subjected to a policy and other women welcoming induction and may have liked to have been induced earlier. ${ }^{39}$ Henderson and Redshaw conducted a secondary analysis of surveys regarding care during delivery, and although they acknowledge the weaknesses inherent in this type of study, they did highlight some important themes that may help in improving care when women are undergoing induction. ${ }^{40}$ Women who were induced were less likely to be satisfied with their birth experience, and cited staff shortages along with feelings of neglect, pain, and anxiety in relation to starting the induction. ${ }^{40}$ They also reported feelings of plans not being followed, wasted effort, and pain, as well as feeling let down and disappointed if unsuccessful. ${ }^{40}$ Shetty et al reported that $40 \%$ of the women they surveyed felt that the speed of their induction was the most important aspect they would change if they needed to undergo another induction..$^{41}$ These studies are biased, but highlight aspects of care where obstetricians and support staff may be able to improve the patient experience, given that management of expectations is crucial in these cases.

\section{Conclusion}

As the proportion of women undergoing induction of labor continues to increase, it is important to improve and develop more effective and rapid induction methods. Staffing, timing, safety, and patient experience of induction of labor can be a challenge, so methods that speed the time to delivery while maintaining maternal and neonatal safety are imperative. It is well established that misoprostol is an effective labor induction agent, although the current dosing methods are flawed in their inability to be completely accurate or discontinued. The $200 \mu \mathrm{g}$ MVI provides controlled release of misoprostol that can be immediately interrupted and is a safe and effective delivery system for women with an unscarred uterus undergoing induction of labor, and is a valuable alternative to currently available labor induction agents.

\section{Disclosure}

DAW is a consultant for Ferring Pharmaceuticals and was a principal investigator for the multicenter Misoprostol Vaginal Insert Consortium for Ferring Pharmaceuticals. MLS reports no conflicts of interest.

\section{References}

1. Hamilton BE, Martin JA, Ventura SJ. Births: preliminary data for 2012. Natl Vital Stat Rep. 2013;62(3):1-20.

2. National Institute for Health and Care Excellence. Guideline CG70: Induction of labour. 2008. Available from: https://www.nice.org.uk/ guidance/cg70/chapter/introduction. Accessed November 18, 2014.

3. Information Services Division, National Services Scotland. Births in Scottish hospitals, year ending 31 March 2013. 2014. Available from: http://www.isdscotland.org/Health-Topics/Maternity-and-Births/Births/. Accessed November 17, 2014.

4. Maternity Statistics, Wales: Method of delivery, 2003-2013. 2014. Available from: http://wales.gov.uk/docs/statistics/2014/140311maternity-method-delivery-2013-en.pdf. Accessed November 17, 2014.

5. National Health Servise Maternity Statistics - England, 2012-2013. 2013. Available from: www.hscic.gov.uk/catalogue/PUB12744. Accessed November 17, 2014. 
6. Osmundson S, Ou-Yang RJ, Grobman WA. Elective induction compared with expectant management in nulliparous women with an unfavorable cervix. Obstet Gynecol. 2011;117(3):583-587.

7. Cheng YW, Kaimal AJ, Snowden JM, Nicholson JM, Caughey AB. Induction of labor compared to expectant management in low-risk women and associated perinatal outcomes. Am J Obstet Gynecol. 2012;207(6):502. e501-e508.

8. Darney BG, Snowden JM, Cheng YW, et al. Elective induction of labor at term compared with expectant management: maternal and neonatal outcomes. Obstet Gynecol. 2013;122(4):761-769.

9. Sanchez-Ramos L, Olivier F, Delke I, Kaunitz AM. Labor induction versus expectant management for postterm pregnancies: a systematic review with meta-analysis. Obstet Gynecol. 2003;101(6):1312-1318.

10. Stock SJ, Ferguson E, Duffy A, Ford I, Chalmers J, Norman JE. Outcomes of elective induction of labour compared with expectant management: population based study. BMJ. 2012;344:e2838.

11. Caughey $\mathrm{AB}$. Induction of labour: does it increase the risk of cesarean delivery? BJOG. 2014;121(6):658-661.

12. Gulmezoglu AM, Crowther CA, Middleton P, Heatley E. Induction of labour for improving birth outcomes for women at or beyond term. Cochrane Database Syst Rev. 2012;6:CD004945.

13. Bailit JL, Grobman W, Zhao Y, et al. Nonmedically indicated induction vs expectant treatment in term nulliparous women. Am J Obstet Gynecol. 2015;212(1):103.e1-e7.

14. Spong CY. Defining "term" pregnancy: recommendations from the Defining “Term” Pregnancy Workgroup. JAMA. 2013;309(23): 2445-2446.

15. Spong CY, Berghella V, Wenstrom KD, Mercer BM, Saade GR. Preventing the first cesarean delivery: summary of a joint Eunice Kennedy Shriver National Institute of Child Health and Human Development, Society for Maternal-Fetal Medicine, and American College of Obstetricians and Gynecologists Workshop. Obstet Gynecol. 2012;120(5): 1181-1193.

16. Kolas T, Hofoss D, Daltveit AK, et al. Indications for cesarean deliveries in Norway. Am J Obstet Gynecol. 2003;188(4):864-870.

17. Mealing NM, Roberts CL, Ford JB, Simpson JM, Morris JM. Trends in induction of labour, 1998-2007: a population-based study. Aust $N$ Z J Obstet Gynaecol. 2009;49(6):599-605.

18. Kelly AJ, Malik S, Smith L, Kavanagh J, Thomas J. Vaginal prostaglandin (PGE2 and PGF2a) for induction of labour at term. Cochrane Database Syst Rev. 2009;4:CD003101.

19. Bishop EH. Pelvic scoring for elective induction. Obstet Gynecol. 1964;24:266-268.

20. Vrouenraets FP, Roumen FJ, Dehing CJ, van den Akker ES, Aarts MJ, Scheve EJ. Bishop score and risk of cesarean delivery after induction of labor in nulliparous women. Am J Obstet Gynecol. 2005;105(4): 690-697.

21. Laughon SK, Zhang J, Troendle J, Sun L, Reddy UM. Using a simplified Bishop score to predict vaginal delivery. Am J Obstet Gynecol. 2011;117(4):805-811.

22. ACOG Committee on Practice Bulletins - Obstetrics. ACOG Practice Bulletin No. 107: induction of labor. Am J Obstet Gynecol. 2009;114 (2 Pt 1):386-397.

23. Smith R. Parturition. N Engl J Med. 2007;356(3):271-283.

24. Thomas J, Fairclough A, Kavanagh J, Kelly AJ. Vaginal prostaglandin (PGE2 and PGF2a) for induction of labour at term. Cochrane Database Syst Rev. 2014;6:CD003101.

Drug Design, Development and Therapy

\section{Publish your work in this journal}

Drug Design, Development and Therapy is an international, peerreviewed open-access journal that spans the spectrum of drug design and development through to clinical applications. Clinical outcomes, patient safety, and programs for the development and effective, safe, and sustained use of medicines are a feature of the journal, which
25. Hofmeyr GJ, Gulmezoglu AM, Pileggi C. Vaginal misoprostol for cervical ripening and induction of labour. Cochrane Database Syst Rev. 2010;10:CD000941.

26. Liu A, Lv J, Hu Y, Lang J, Ma L, Chen W. Efficacy and safety of intravaginal misoprostol versus intracervical dinoprostone for labor induction at term: a systematic review and meta-analysis. $J$ Obstet Gynaecol Res. 2014;40(4):897-906.

27. Powers BL, Wing DA, Carr D, Ewert K, Di Spirito M. Pharmacokinetic profiles of controlled-release hydrogel polymer vaginal inserts containing misoprostol. J Clin Pharmacol. 2008;48(1):26-34.

28. Rayburn WF, Powers BL, Plasse TF, Carr D, Di Spirito M. Pharmacokinetics of a controlled-release misoprostol vaginal insert at term. J Soc Gynecol Investig. 2006;13(2):112-117.

29. US Food and Drug Administration. Full revised misoprostol (Cytotec) label - Searle. 2002. Available from: www.accessdata.fda.gov/ drugsatfda_docs/label/2002/19268slr037.pdf. Accessed November 18, 2014.

30. Castaneda CS, Izquierdo Puente JC, Leon Ochoa RA, Plasse TF, Powers BL, Rayburn WF. Misoprostol dose selection in a controlledrelease vaginal insert for induction of labor in nulliparous women. Am J Obstet Gynecol. 2005;193(3 Pt 2):1071-1075.

31. Frohn WE, Simmons S, Carlan SJ. Prostaglandin E2 gel versus misoprostol for cervical ripening in patients with premature rupture of membranes after 34 weeks. Obstet Gynecol. 2002;99(2):206-210.

32. Wing DA, Powers BL, Rayburn WF. Determining dose and endpoints of a controlled-release misoprostol vaginal insert for a phase III trial. J Reprod Med. 2008;53(9):695-696.

33. Ewert K, Powers B, Robertson S, Alfirevic Z. Controlled-release misoprostol vaginal insert in parous women for labor induction: a randomized controlled trial. Obstet Gynecol. 2006;108(5):1130-1137.

34. Wing DA; Misoprostol Vaginal Insert Consortium. Misoprostol vaginal insert compared with dinoprostone vaginal insert: a randomized controlled trial. Obstet Gynecol. 2008;112(4):801-812.

35. Pevzner L, Alfirevic Z, Powers BL, Wing DA. Cardiotocographic abnormalities associated with misoprostol and dinoprostone cervical ripening and labor induction. Eur J Obstet Gynecol Reprod Biol. 2011; 156(2):144-148.

36. Wing DA, Miller H, Parker L, Powers BL, Rayburn WF; Misoprostol Vaginal Insert Miso-Obs-204 Investigators. Misoprostol vaginal insert for successful labor induction: a randomized controlled trial. Obstet Gynecol. 2011;117(3):533-541.

37. Stephenson ML, Powers BL, Wing DA. Fetal heart rate and cardiotocographic abnormalities with varying dose misoprostol vaginal inserts. J Matern Fetal Neonatal Med. 2013;26(2):127-131.

38. Wing DA, Brown R, Plante LA, Miller H, Rugarn O, Powers BL. Misoprostol vaginal insert and time to vaginal delivery: a randomized controlled trial. Obstet Gynecol. 2013;122(2 Pt 1):201-209.

39. Gatward H, Simpson M, Woodhart L, Stainton MC. Women's experiences of being induced for post-date pregnancy. Women Birth. 2010; 23(1):3-9.

40. Henderson J, Redshaw M. Women's experience of induction of labor: a mixed methods study. Acta Obstet Gynecol Scand. 2013;92(10): 1159-1167.

41. Shetty A, Burt R, Rice P, Templeton A. Women's perceptions, expectations and satisfaction with induced labour - a questionnaire-based study. Eur J Obstet Gynecol Reprod Biol. 2005;123(1):56-61.

has also been accepted for indexing on PubMed Central. The manuscript management system is completely online and includes a very quick and fair peer-review system, which is all easy to use. Visit http://www.dovepress.com/testimonials.php to read real quotes from published authors. 